\title{
Similarities and differences in structure, expression, and functions of VLDLR and ApoER2
}

\author{
Sunil S Reddy ${ }^{1}$, Teal E Connor ${ }^{2}$, Edwin J Weeber ${ }^{3}$ and William Rebeck ${ }^{2^{*}}$
}

\begin{abstract}
Very Low Density Lipoprotein Receptor (VLDLR) and Apolipoprotein E Receptor 2 (ApoER2) are important receptors in the brain for mediating the signaling effects of the extracellular matrix protein Reelin, affecting neuronal function in development and in the adult brain. VLDLR and ApoER2 are members of the low density lipoprotein family, which also mediates the effects of numerous other extracellular ligands, including apolipoprotein $\mathrm{E}$. Although VLDLR and ApoER2 are highly homologous, they differ in a number of ways, including structural differences, expression patterns, alternative splicing, and binding of extracellular and intracellular proteins. This review aims to summarize important aspects of VLDLR and ApoER2 that may account for interesting recent findings that highlight the unique functions of each receptor.
\end{abstract}

\section{Introduction}

Very Low Density Lipoprotein Receptor (VLDLR) and Apolipoprotein E Receptor 2 (ApoER2; also known as LRP8) are members of the LDL receptor family, a group associated with cellular cholesterol homeostasis [1]. LDL receptor family members are type I transmembrane receptors and have five highly conserved structural domains: an extracellular $\mathrm{N}$-terminal ligand-binding domain with cysteine-rich repeats, an epidermal growth factor (EGF) domain, an O-linked sugar domain, a single transmembrane sequence, and a cytoplasmic domain containing an NPxY motif. The overall sequence homology between VLDLR and ApoER2 is around 50\% [2].

VLDLR and ApoER2 are primarily recognized for their role in neural development through Reelin signaling, a process that is responsible for proper positioning of newly generated neurons leading to the inside-out formation of the six-layered neocortex [3]. Reelin is a glycoprotein secreted by Cajal-Retzius cells that signals neurons to migrate radially past earlier-generated cells to arrive at the appropriate lamina [4]. Reelin signaling is also important for alignment of pyramidal neurons in the hippocampus and Purkinje cells of the cerebellum [3]. In this pathway, VLDLR and ApoER2 are cell surface receptors for Reelin [5,6]. Interaction with Reelin induces VLDLR

\footnotetext{
* Correspondence: gwr2@georgetown.edu

${ }^{2}$ Department of Neuroscience; Georgetown University Medical Center, 3970 Reservoir Rd, NW, Washington, DC, 20007, USA

Full list of author information is available at the end of the article
}

and ApoER2 to bind the adaptor protein Dab1 at an NPxY motif on their cytoplasmic tails $[7,8]$. Binding of Dab1 subsequently leads to activation of Src family tyrosine kinases (SFKs) and other kinases that phosphorylate the adaptor protein at its tyrosine residues [9]. VLDLR and ApoER2 are the exclusive Reelin signaling receptors, and, consistent with their high extracellular sequence homology, bind Reelin with similar affinities [10]. Mutations or deletions of the Reelin gene, the Dab1 gene, or the genes for both VLDLR and ApoER2 result in improper neuronal migration, cortical laminating defects, and cerebellar hypoplasia $[5,7,11,12]$.

Secreted Reelin can form complexes, including homodimers, which allows association and clustering of multiple receptors simultaneously $[9,13]$. This receptor clustering is necessary for the phosphorylation of Dab1 and its subsequent interaction with kinases [9]. Ligand binding to VLDLR and ApoER2 also initiates clathrin-dependent receptor endocytosis, which likely modulates further ligand signaling [14]. Dab1 phosphorylation following Reelin activation of apoE receptors leads to Dab1 degradation by proteosomes [15]. Thus, there are several mechanisms for regulating the Reelin signaling mechanisms.

Studies of the developing CNS suggest that VLDLR and ApoER2 serve overlapping functions in controlling neuronal migration. However, several recent studies have demonstrated clear differences in VLDLR and ApoER2 splicing, localization, interactors, and trafficking. The differences in receptor function during development also 
translate into differences in adult brain function. Both VLDLR and ApoER2 are receptors for apolipoprotein E (apoE), the leading genetic risk factor for Alzheimer's disease (AD) [16], and these receptors may play different roles in modulating the risk associated with apoE. Here, we explore VLDLR, ApoER2, and importantly, the distinctions between them.

\section{Comparison of VLDLR and ApoER2 proteins Structure}

Full length human $V L D L R$ mRNA encodes a protein of 873 amino acids ([17]; NCBI Accession NM_003383.3). VLDLR has eight cysteine-rich ligand-binding repeats (LBRs) of approximately 40 amino acids each, an EGF region with three cysteine rich repeats, a 46 amino acid O-linked glycosylation domain with numerous threonine and serine residues, a 22 amino acid transmembrane domain, and a 54 amino acid cytoplasmic domain containing the NPxY motif (Figure 1) [18]. The first 27 amino acids of the $\mathrm{N}$-terminal are hydrophobic and serve as the signal peptide. A glycine residue is believed to constitute the $\mathrm{N}$-terminus of the mature receptor. There is $97 \%$ amino acid identity between VLDLR in mouse and human [17].

The full length human ApoER2 mRNA encodes a protein of 870 amino acid residues (NCBI Accession NM_004631.3). ApoER2 has the same overall domain structure as VLDLR, with several important differences. ApoER2 contains a ligand-binding domain of eight LBRs (only five LBRS are ever observed in the cDNA due to splicing out of LBRs 4-6; see Figure 1), an EGF domain with three cysteine-rich repeats, an O-linked glycosylation domain of 89 amino acids, a transmembrane domain of 24 amino acids, and a cytoplasmic domain of
115 amino acids (Figure 1) [2]. The signal peptide consists of approximately 40 amino acids. Homology between ApoER2 in mouse and human is approximately 90\%. In humans, VLDLR and ApoER2 share a roughly $50 \%$ primary sequence homology, with the O-linked glycosylation domain (21\%) and transmembrane domain (35\%) being the least identical [2].

Thus, the gene sequences of VLDLR and ApoER2 differ most dramatically in their O-linked glycosylation domains; this domain in ApoER2 is more than twice the size of that in VLDLR.

\section{Distribution (Temporal and Spatial)}

$V L D L R$ mRNA transcripts are most abundant in brain with high expression in the heart and skeletal muscle as well (Table 1). These tissues have relatively high levels of free lipids, supporting a role of VLDLR in metabolism of cholesterol and fatty acids [18]. Within the adult brain, VLDLR mRNA is found in nearly all regions, with highest expression in the cortex and cerebellum (Table 2 ). Within these regions, VLDLR is found on microglia and region-specific pyramidal neurons [19], as well as in neuroblasts, matrix cells, Cajal-Retzius cells, glioblasts, astrocytes, and oligodendrocytes [18,20] (Table 3). Subcellularly, VLDLR is in non-lipid raft fractions of cell membranes [14].

ApoER2 mRNA is present exclusively in CNS, placenta, and testis [2] (Table 1). Immunohistochemical analysis reveals ApoER2 expression in the hippocampus, cerebellum, mitral cell layer of the olfactory bulb, neocortex (cell bodies and dendrites), and cortical neurons [21,22] (Table 2). In the hippocampus, ApoER2 is found in granule cells of the dentate gyrus and pyramidal cells of all CA subfields [21]. In the cerebellum, ApoER2 is found densely in Purkinje cells [2,21] (Table 3). Subcellularly,

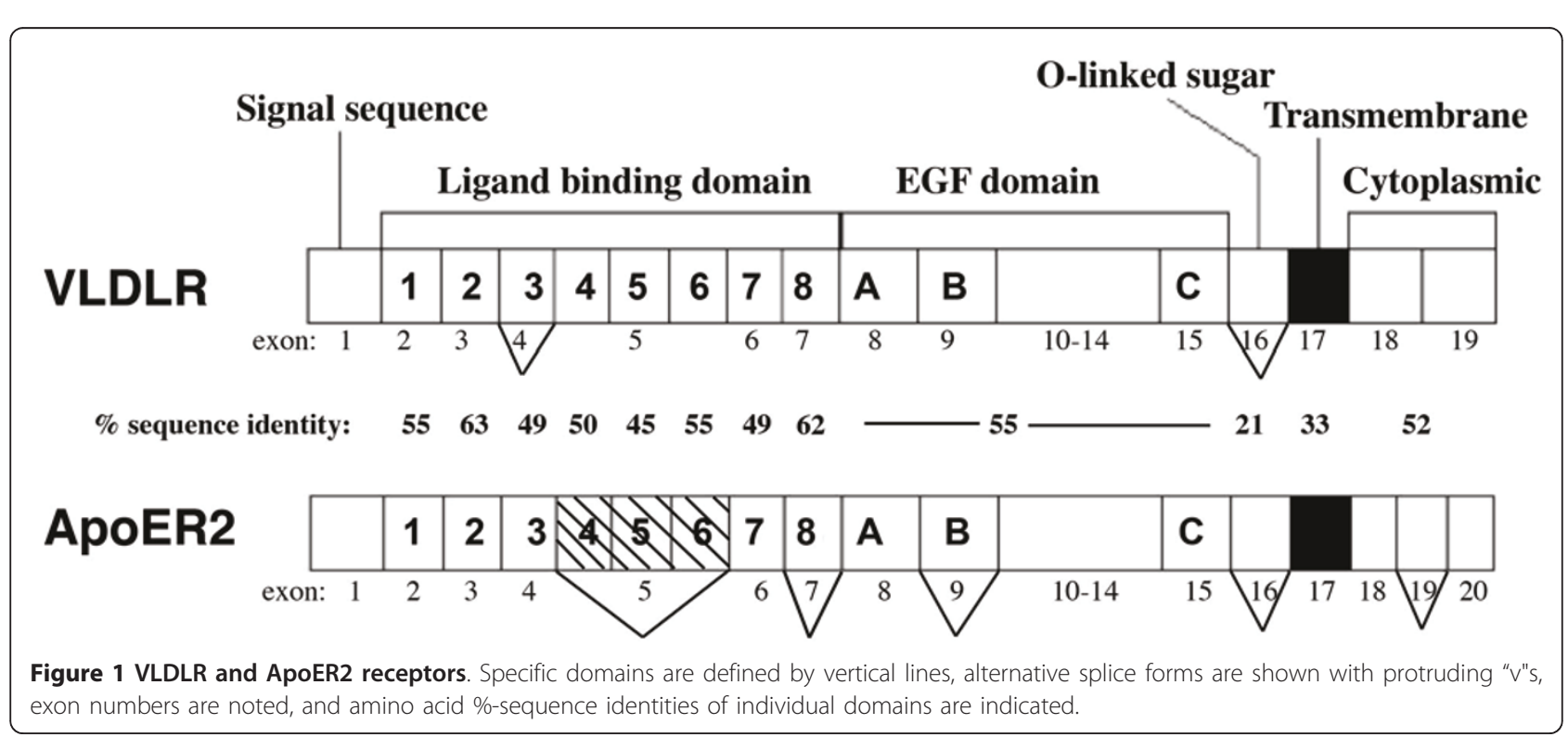


Table 1 Expression of VLDLR and ApoER2 in mouse organs. +/-, +, and ++ represent increasing levels of expression $[2,18]$

\begin{tabular}{cccccccccccc}
\hline & Brain & Heart & Testis & Ovary & Kidney & Muscle & Placenta & Lung & Adipose Tissue & Small Intestine & Liver \\
\hline VLDLR & ++ & ++ & + & + & ++ & ++ & - & + & + & $+/-$ & $+/-$ \\
\hline ApoER2 & ++ & - & ++ & $+/-$ & - & - & + & - & - & - & - \\
\hline
\end{tabular}

ApoER2 is differentially sorted into lipid raft fractions of cell membranes [14].

VLDLR and ApoER2 also have different patterns of tissue expression over development (Table 4). At E12 of development both VLDLR and ApoER2 are expressed at low levels in the preplate. From E12.5-E13.5, ApoER2 is expressed in the inner and middle locations of the cortex; and at E15, ApoER2 is in the olfactory bulb and in medial cortical fields. At E15, VLDLR is seen in the hippocampal anlage-medial cortex, paleocortex, subplate of the upper cortical plate, and weakly in the neocortical plate and Cajal-Retzius cells. From E16.5-E17 ApoER2 expression is in the outermost cortex as well as deeper cerebellar layers, and at E18, ApoER2 is expressed in the same regions as VLDLR was at E15, with the exception of Cajal-Retzius cells. VLDLR at E18 maintains the same as its E15 expression pattern but with stronger expression in Cajal-Retzius cells, and signal in Purkinje cells. Postnatally, from P0-P6, both VLDLR and ApoER2 are expressed in the subplate and pyramidal cells of layers III and V; VLDLR is additionally in Cajal-Retzius and Purkinje cells postnatally [22,23]. Thus, VLDLR is expressed earlier in development and is more highly expressed in Cajal-Retzius cells than ApoER2.

\section{Splicing}

Both VLDLR and ApoER2 undergo alternative splicing to produce several transcript variants. Four transcripts of $V L D L R$ (I-IV) have been defined [20]. VLDLR-I, lacks none of the exons, $V L D L R-I I$ lacks exon 16 encoding the O-linked sugar domain, $V L D L R$-III lacks exon 4 encoding the third ligand-binding repeat, and VLDLR-IV lacks both exons 4 and 16. In adult mouse brain, over half (75\%) of transcripts lack exon 16 and the next most common form lacks both exons 4 and 16. Thus, most of the VLDLR present in the brain lacks the O-linked sugar domain and thus would not be expected to be glycosylated. Astrocytes exhibit less splicing of exon 4 and exon

Table 2 Regional expression of VLDLR and ApoER2 within adult mouse brain

\begin{tabular}{cccccccccc}
\hline Brain: & TH & CX & ST & HI & HY & CB & BR & OB & SE \\
\hline VLDLR & + & + & + & + & + & + & + & - & + \\
\hline ApoER2 & - & + & - & + & - & + & - & + & -
\end{tabular}

$\mathrm{TH}=$ Thalamus, $\mathrm{CX}=$ Cerebral Cortex, $\mathrm{ST}=$ Striatum, $\mathrm{HI}=$ Hippocampus, $\mathrm{HY}=$ Hypothalamus, $\mathrm{CB}=$ Cerebellum, $\mathrm{BR}=$ Brainstem, $\mathrm{OB}=$ Olfactory bulb, $\mathrm{SE}=$ Septum $[2,18]$.
16 than neurons [20]. VLDLR containing exon 16 is increased in normal aging and Alzheimer's disease [24].

ApoER2 displays a more complex splicing pattern. Exon 5 (Figure 1), containing ligand-binding repeats $4-6$, is spliced out of all transcripts [21,25]. The eighth LBR is spliced out during very early stages of development (E12 in mouse). Some transcripts in brain and all transcripts in placenta contain a 13 amino acid insert containing a furin cleavage site in place of ligand binding repeat 8 (exon 7) [25]. Exon 9, encoding an EGF repeat, and exon 16 , containing the $\mathrm{O}$-linked sugar domain, can be alternately spliced out [21], resulting in a smaller, differentially glycosylated precursor form found in the ER [26]. Splicing of the ligand-binding and EGF repeats alters binding affinity to ligands, suggesting the different transcripts may function in fine-tuning receptor-ligand interactions [27]. Finally, ApoER2 contains an alternatively spliced exon (19) that encodes a 59 amino acid domain in the cytoplasmic tail $[2,21,25]$. The exon 19 domain is proline-rich and ends 10 amino acids before the C-terminus of ApoER2. The presence of this domain promotes interactions of ApoER2 with the c-jun N-terminal kinase (JNK) interacting proteins, JIP1 and JIP2, and the synaptic protein, PSD-95 [28,29] (see below).

Thus, differential splicing of ApoER2 and VLDLR produce proteins with different numbers of LBRs and very different cytoplasmic domains.

\section{Interacting proteins}

VLDLR and ApoER2 interact with a similar, but not identical, number of proteins [30]. Extracellularly, these receptors mediate the effects of specific ligands. Intracellularly, protein interactions alter receptor trafficking and processing [31]. In addition, proteolytic enzymes act on the receptors to generate $\mathrm{N}$ - and C-terminal fragments $[32,33]$. We summarize some of these interacting proteins below (see also Table 5 and Figure 2).

Extracellular Reelin is a large extracellular matrix protein $(\sim 400 \mathrm{kDa})$ expressed by Cajal-Retzius cells during embryonic development and by interneurons in the postnatal brain $[3,6]$. Reelin can bind to both VLDLR and ApoER2 in the absence of a co-receptor $[6,34]$, although a co-receptor may be needed for efficient binding [35]. Reelin binds to the first ligand binding repeat of VLDLR and ApoER2; this interaction depends on a specific lysine residue in Reelin (amino acid 2467) [36]. Reelin is cleaved at numerous sites to generate a series of fragments $[37,38]$. Reelin fragments bind equally to 
Table 3 Cellular expression of VLDLR and ApoER2 within mouse brain $[2,18,21]$

\begin{tabular}{ccccccc}
\hline Glia & $\begin{array}{c}\text { Cortical Plate } \\
\text { Neurons }\end{array}$ & $\begin{array}{c}\text { Hippocampal Pyramidal } \\
\text { Neurons }\end{array}$ & $\begin{array}{c}\text { Cajal-Retzius } \\
\text { cells }\end{array}$ & $\begin{array}{c}\text { Olfactory Mitral } \\
\text { Cells }\end{array}$ & $\begin{array}{c}\text { Cerebellar Purkinje } \\
\text { Cells }\end{array}$ \\
\hline VLDLR & + & ++ & + & ++ & - & + \\
\hline ApoER2 & - & ++ & + & - & ++ & ++ \\
\hline
\end{tabular}

both VLDLR and ApoER2, but native full-length Reelin binds with higher affinity to ApoER2 (LBRs-12378) than to VLDLR [38]. Reelin fragments with cleaved C-terminal regions bind VLDLR and ApoER2 with a significantly higher affinity than full-length Reelin [27].

Apolipoprotein $\mathrm{E}$ (apoE) is a component of lipoproteins involved in phospholipid and cholesterol homeostasis [39]. VLDLR binds and internalizes all human isoforms of apoE (E2, E3, E4) with high affinity, including lipidfree forms, and it does so through LBRs 5-8 [39]. The ApoER2 LBRs binds apoE containing $\beta$-VLDL with high affinity, specifically the ApoER2 splice variants that lack LBR's 4-6 and LBR 8 [25]. ApoE bound to receptors may be internalized and degraded, recycled to the cell surface, or remain intracellular for extended periods [40]. ApoE leads to the cleavage of both VLDLR and ApoER2 to generate secreted forms of these receptors [33].

Thrombospondin and F-spondin are extracellular matrix proteins. Thrombospondins are a family of trimeric or pentameric proteins that are involved in cellcell and cell-matrix communication, and affect processes such as neurite outgrowth, neuronal migration, and synaptogenesis $[41,42]$. Thrombospondin-1 binds to the ligand binding repeats of VLDLR and ApoER2, and competes with Reelin binding [43]. Like Reelin, Thrombospondin can induce Dab1 phosphorylation although not the subsequent Dab1 degradation [43]. F-spondin is a secreted molecule whose $\mathrm{C}$-terminal domain is similar to repeats found in Thrombospondin; its $\mathrm{N}$-terminal domain is homologous to a domain in Reelin that promotes dimerization [44]. The thrombospondin domain of F-spondin interacts with the LBR domain of ApoER2 [45] and may bind to both VLDLR and ApoER2 in the rostral migratory stream [46]. Like Reelin and Thrombospondin, F-spondin can induce activation of Dab1 [47].
Selenium is a ligand for ApoER2 through its transporter, Selenoprotein P (Sepp1). Sepp1 transports selenium from the liver to other target tissues such as the testis and brain [48]. ApoER2 knockout mice have phenotypic similarities to Sepp1 knockout mice such as lower selenium levels in areas where ApoER2 is normally expressed (the brain and the testis) [49]. When fed a selenium deficient diet, ApoER2 knockouts had neurological problems, progressive neurodegeneration, and shortened survival, similar to Sepp1 knockouts on the same diet $[49,50]$. ApoER2 mediates the endocytosis of Sepp1 [48].

Membrane Spanning Domain Secretases promote cleavage of VLDLR and ApoER2 [32], and these proteolytic events can be induced by ligand binding [33]. A soluble extracellular fragment is generated by metalloproteinase activity; cleavage of ApoER2 occurs at small levels even when unstimulated, but after Reelin stimulation cleavage significantly increases [33]. $\gamma$-secretase cleaves in the intramembrane regions to generate soluble intracellular domains [32]. This cleavage was not observed with a monovalent ligand, the receptor-associated protein RAP, suggesting the importance of multivalent, clusteringligands in this process [9]. ApoE leads to release of extracellular domains and increased accumulation of C-terminal fragments of both VLDLR and ApoER2, but with less cleavage apparent for VLDLR than for ApoER2 [33].

Proteolysis of VLDLR and ApoER2 can also be promoted by extracellular interactions of the receptors with the proprotein convertase PCSK9 [51]. PCSK9 was first associated with degradation of the LDL receptor [52], and is regulated by SREBP [53]. In addition, proteosomal degradation of VLDLR and ApoER2 can be induced by an E3 ubiquitin ligase (IDOL, Inducible Degrader of the LDL Receptor) [54]. IDOL is regulated under the LXR system [54], which is important for cellular cholesterol

Table 4 Temporal and spatial expression of VLDLR and ApoER2 within developing embryonic mouse brain [22,23]

\begin{tabular}{|c|c|c|c|c|c|c|}
\hline $\begin{array}{l}\text { Developmental } \\
\text { day }\end{array}$ & E12 & E12.5-13.5 & E15-E15.5 & E16.5-E17 & E18 & P0-P6 \\
\hline VLDLR & $\begin{array}{l}\text { Low } \\
\text { expression } \\
\text { in preplate }\end{array}$ & $\begin{array}{l}\text { Intermediate } \\
\text { zone and } \\
\text { cortical plate }\end{array}$ & $\begin{array}{c}\text { Developing hippocampus; } \\
\text { palaeocortex; neocortical plate; } \\
\text { Cajal-Retzius cells; subplate; deep } \\
\text { layers of cerebellum }\end{array}$ & $\begin{array}{l}\text { All areas as } \\
\text { E15 }\end{array}$ & $\begin{array}{l}\text { All areas as E15, plus: } \\
\text { Stronger expression in } \\
\text { Cajal-Retzius cells; } \\
\text { Purkinje cells }\end{array}$ & $\begin{array}{l}\text { Subplate and pyramidal } \\
\text { cells of layers III and V; } \\
\text { Cajal-Retzius cells; } \\
\text { Purkinje cells }\end{array}$ \\
\hline ApoER2 & $\begin{array}{l}\text { Low } \\
\text { expression } \\
\text { in preplate }\end{array}$ & $\begin{array}{l}\text { Inner and } \\
\text { middle } \\
\text { locations of } \\
\text { cortex }\end{array}$ & $\begin{array}{l}\text { Medial cortical fields; olfactory } \\
\text { bulb; ubiquitously in cerebellum }\end{array}$ & $\begin{array}{l}\text { Outermost } \\
\text { cortex; } \\
\text { deeper } \\
\text { cerebellar } \\
\text { layers }\end{array}$ & $\begin{array}{l}\text { Developing } \\
\text { hippocampus; } \\
\text { palaeocortex; } \\
\text { neocortical plate, } \\
\text { subplate }\end{array}$ & $\begin{array}{l}\text { Subplate and pyramidal } \\
\text { cells of layers III and V }\end{array}$ \\
\hline
\end{tabular}


Table 5 Interactions of various molecules with VLDLR and ApoER2

\begin{tabular}{|c|c|c|c|c|}
\hline VLDLR & & Ectodomain Interactor & & ApoER2 \\
\hline unknown & + & Reelin & + & LBR1 \\
\hline LBR & + & Thrombospondin F-spondin & + & LBR \\
\hline \multirow[t]{2}{*}{ LBR 5-8 } & + & ApoE & + & LBR 1-3, 7 \\
\hline & - & selenoprotein & + & unknown \\
\hline VLDLR & & $\begin{array}{l}\text { Transmembrane } \\
\text { Interactor }\end{array}$ & & ApoER2 \\
\hline Releases intracellular domains & + & $\gamma$-secretase & + & Releases intracellular domains \\
\hline Releases extracellular domains & + & $\alpha$-secretase & + & Releases extracellular domains \\
\hline VLDLR & & Cytoplasmic Interactor & & ApoER2 \\
\hline \multirow[t]{2}{*}{$\begin{array}{l}\text { PTB domain binds 14-residue peptide around the } \\
\qquad \text { NPXY }\end{array}$} & + & Dab1 & + & $\begin{array}{l}\text { PTB domain binds 14-residue peptide around the } \\
\qquad \mathrm{NPXY}\end{array}$ \\
\hline & - & Dab2 & + & PTB domain binds NPxY of ApoER2 \\
\hline \multirow[t]{3}{*}{ NPXY followed by leucine } & + & Pafah1b2 \& Pafah1b3 & - & NPxY followed by arginine \\
\hline & - & $J|P-1, J| P-2$ & + & Exon 19 \\
\hline & - & PSD-95 & + & Exon 19 \\
\hline$N P x Y$ & + & FE65 & + & $N P x y$ \\
\hline
\end{tabular}

homeostasis. Thus, VLDLR and ApoER2 levels can be regulated in sterol-responsive ways, similar to the process for the LDL receptor.

Intracellular Disabled-1 binds to VLDLR and ApoER2 intracellularly at NPxY motifs through its phosphotyrosine-binding (PTB) domain [8]. The PTB domain of Dab1 contains a hydrophobic groove and this structure creates the preference for the ApoER2 C-terminal helix [55]. Dab1 also binds Src and Fyn kinases, which are important in the downstream organizational effects of Reelin signaling [56]. The PTB structure has steric interference with phosphorylated tyrosines, explaining the preference for the NPxY motifs containing unphosphorylated tyrosines [55]. The presence of extracellular ligands such as Reelin increases the interaction of ApoER2 with Dab1 $[57,58]$. Reelin-binding of VLDLR and ApoER2 result in similar and robust levels of Dab1 phosphorylation, and receptor-clustering mimics this effect [26]. Dab1 promotes surface localization of ApoER2 and its subsequent cleavage by $\alpha$-secretase [58].

Disabled-2 (Dab2), like its homolog Dab1, is a cytosolic adaptor protein. Dab2 is found at various locations in the embryonic mouse CNS throughout development, including the developing hindbrain, floor plate of the neural tube, choroid plexus, subcommissural organ, and pineal gland [59]. Like Dab1, Dab2 is thought to play a role in organization and cell positioning by signaling through LDL receptor family members [60], but it does not compensate for loss of Reelin signaling. Dab2 has been shown to regulate the MAPK pathway as well as Src activity [61]. Dab2 is also necessary for the internalization of ApoER2; the PTB domain of Dab2 interacts with the NPxY motif of ApoER2 and leads to internalization independent of exon 19 [62]. Dab2 does not bind VLDLR [60].

The Pafah1b complex of proteins consists of Lis 1 (encoded by the Pafah1b1 gene) and two catalytic $\alpha$ subunits (encoded by Pafah1b2 and Pafah1b3) [63]. Heterozygous mutations of Pafah1b1 cause lissencephaly and a reduced number of cortical gyri, similar to the reeler phenotype [64]. In vitro, the $\alpha$-subunits bind VLDLR at its NPVYL domain but not ApoER2, which has an NPVYR sequence [65]. Mouse models also support the conclusion that Pafah1b is functionally connected to VLDLR but not ApoER2 [65].

JIP-1 and JIP-2 act as molecular scaffolds in the JNKsignaling pathway [66]. JIP-1 and JIP-2 were identified in a yeast two-hybrid assay as interactors with the alternatively-spliced exon 19 of ApoER2, and thus do not bind VLDLR, which lacks this domain [31]. The PID domain, rather than the SH3 domain, of JIP-2 was found to be responsible for the interaction with exon 19 [28]. The binding of JIPs and Dab1 to ApoER2 suggests that ApoER2 forms a scaffold for various interactors at the cell surface [28].

PSD-95 is another adaptor protein that interacts preferentially with exon 19 of ApoER2 [29,31,67]. The first PDZ (PDZ1) domain of PSD-95 is responsible for the interaction with the intracellular exon 19 of ApoER2 [67]. PDZ2 of PSD-95 binds the NR2 subunit of NMDA receptors, possibly responsible for the complexes of ApoER2, NR2A, and PSD-95 formed in post-synaptic densities [29]. 


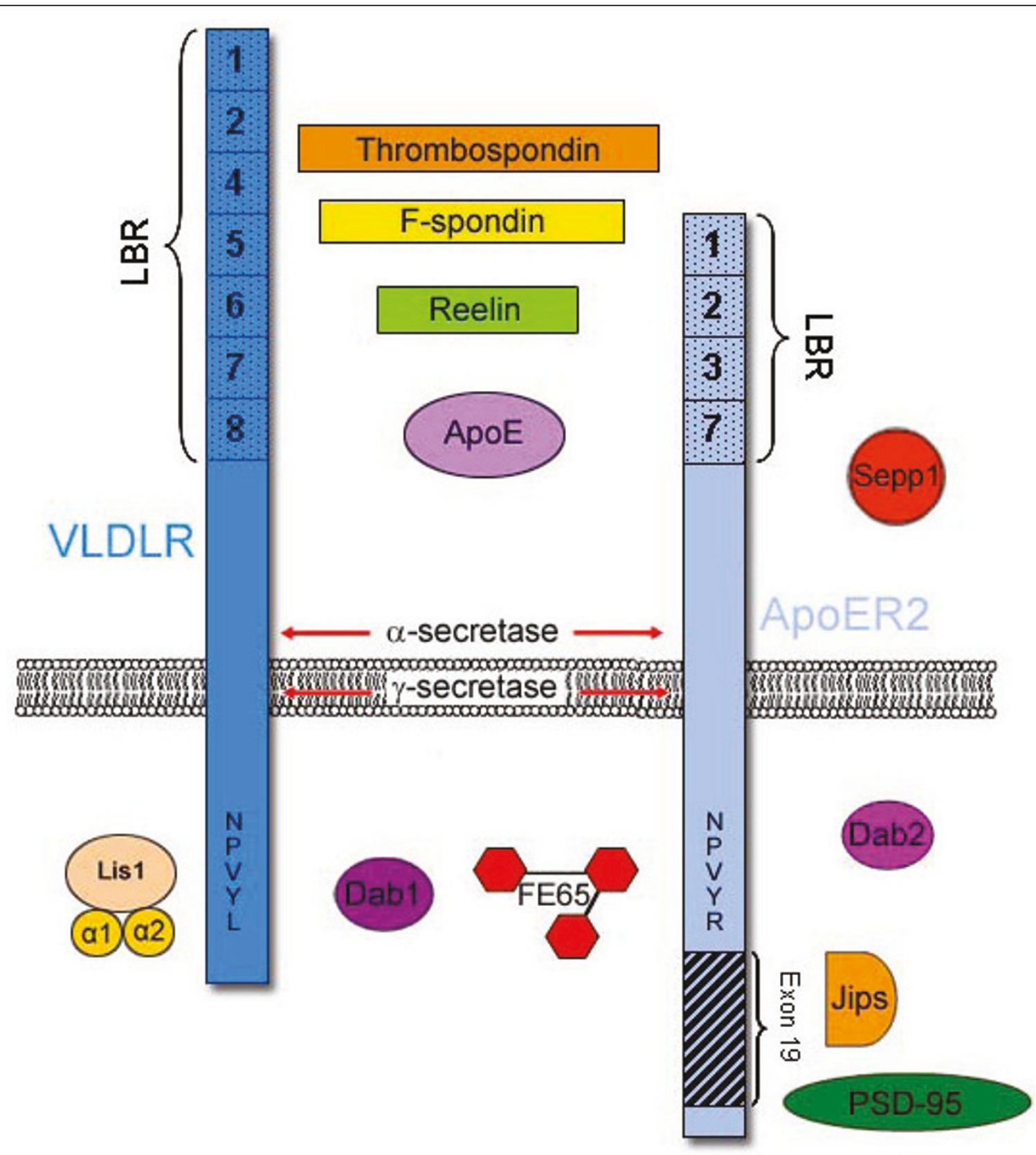

Figure 2 VLDLR and ApoER2 interacting proteins. Some of the extracellular and intracellular proteins that interact with VLDLR and ApoER2 are indicated.

FE65 has three functional domains: two PTB domains, and one WW domain [68]. FE65 binds to NPxY sequences in members of the LDL receptor family via its PTB1 domain $[31,69]$. FE65 interacts with ApoER2 [31,69] and VLDLR (GWR, unpublished data). The other domains of FE65 are important for linking apoE receptors to other proteins, such as the amyloid precursor protein via PTB2 [70], and to the cytoskeleton via the WW domain, affecting cell movement [71]. Knock- out of FE65 family members results in lissencephaly [72], as for several of the other proteins that interact with apoE receptors (see above).

\section{Unique functions of VLDLR and ApoER2}

One of the main differences between VLDLR and ApoER2 is that ApoER2 is restricted to the brain, testis, and placenta whereas VLDLR is expressed in tissues throughout the body. Both receptors are widely 
expressed in the brain, both during development and in the adult. Knockout mouse models of only ApoER2 or only $V L D L R$ do not show the dramatic neuronal migration defects seen in the mice lacking both receptors, a phenocopy of Reelin and Dab1 knockouts [5]; this observation led to the hypothesis that the receptors have overlapping functions in the brain. However, several recent studies have begun to define distinct functions of VLDLR and ApoER2; we will discuss these distinctions in this section.

\section{Contributions to neuronal migration}

Reelin interacts extracellularly with VLDLR and ApoER2, promoting Dab1 phosphorylation intracellularly, and resulting in downstream effects that regulate proper migration of neurons during development $[6,34,73]$. As mentioned, double VLDLR/ApoER2 knock-outs show the full reeler phenotype, similar to animals lacking Reelin or Dab1 [74]. However, analyses of the single knock-out mouse models provide insight into different functions of ApoER2 and VLDLR. Both ApoER2 and VLDLR knockouts have smaller, less foliated cerebella, less cortical lamination, and a splitting of the CA1 layer of the hippocampus [5]. However, the cortical and hippocampal defects were more pronounced in the ApoER2 knockouts, and the cerebellar defect was more pronounced in the VLDLR knock-outs [5].

In addition to these deficits, the VLDLR knock-out neurons demonstrated greater invasion of migrating cortical neurons into the marginal zone [5,23]. Furthermore, fate mapping demonstrated that in ApoER2 knock-out mice, the late-born neurons fail to migrate properly in the cortex [23]. In VLDLR knockouts, the early-born cells ended up in an organized layer of the inner cortex (similar to wild-type animals), suggesting that VLDLR does not have a substantial effect on the limited migration of early-born neurons [23]. VLDLR is primarily expressed in the intermediate zone and the cortical plate adjacent to Reelin-expressing cells in the marginal zone [5]. These observations support a hypothesis that VLDLR mediates a neuronal "stop signal" [23]. In WT mice, ApoER2 receptors are most strongly expressed at E16.5 and E18.5, the stage when late-born neurons reach the superficial layers of the outer cortex. In the ApoER2 knock-out, the early-generated layers formed with minor deficits but late-generated layers were highly disrupted [23]. Antibodies against molecules of the radial glial scaffold revealed no abnormal arrangement of the radial glial cells. In ApoER2 knock-outs there is strong disruption of the radial alignment of the cortical neurons; this phenotype is not seen in the VLDLR-deficient cortex in which neurons are distributed radially [5]. Furthermore, neurons in ApoER2 knock-outs are packed into horizontal layers while the $V L D L R$ knock-outs do not demonstrate discernable cortical lamina [5].
Human mutations in the Reelin gene (RELN) gene cause neuronal migration defects, producing alterations in the architecture of the cortex and cerebellum [75]. The structural phenotype of lissencephaly, malformed hippocampus, and cerebellar hypoplasia is associated with a clinical phenotype of hypotonia, ataxia, and severe mental retardation [75]. Humans have also been identified with homozygous deletion of the $V L D L R$ gene [76]. The VLDLR deletion causes a more mild cerebral gyral simplification, less cerebellar hypoplasia, and unremarkable changes to the hippocampus, compared with the RELN mutation [76]. Thus, the observations with mouse knock-out models support the findings in human genetic diseases.

\section{Pafah1b effects on neuronal migration via VLDLR}

Several of the proteins that interact with VLDLR and ApoER2 have been identified through mouse knock-out models that demonstrate effects on neuronal migration. The lissencephaly phenotype of Pafah1b1 heterozygous mutants sparked interest in exploring the relationship between the Pafah1b complex and the Reelin pathway, including the VLDLR and ApoER2 receptors [64]. The Pafah $1 b 1^{+/-} ; A p o E R 2^{-/-}$double mutants had severe deficits in the forebrain, including inversion of cortical-lamina and hypercellularity of layer I similar to the reeler-like phenotype of an ApoER2;VLDLR double knock-out. However, Pafah $1 b 1^{+/-} ; V L D L R^{-/-}$double mutants were mostly normal. The Pafah $1 \mathrm{b1}^{+/-} ; \mathrm{ApoER2} 2^{-/-}$mutants still underwent Dab1 phosphorylation when stimulated with Reelin (unlike in reeler mice), demonstrating that signaling was still intact (via VLDLR) but was not enough for proper cortical layer formation (requiring Lis1). The $\alpha$ subunits serve as adapter-molecules by bringing Lis1 to VLDLR; one of the subunits ( $\alpha 2)$ binds to Dab1 [77]. The intact signaling suggests Lis1 is downstream of VLDLR and SRKs [65]. In humans, deletions and duplications of the PAFAH1B1 also result in neuronal migration defects, leading to a reduction in the number of cortical gyri $[63,78,79]$. Like the human $V L D L R$ homozygous deletion [76], the PAFAH1B1 heterozygous deletion causes a somewhat milder phenotype than RELN mutations [75]. Thus, the Pafah1b complex mediates downstream effects of VLDLR on neuronal migration, but is not necessary for the function of ApoER2.

\section{Lipid-raft sorting}

Lipoprotein receptors are associated with clathrin-coated pits, indicative of a role in ligand endocytosis and degradation. However, ApoER2 is only found in caveolae-rich membrane fractions $[26,80]$, distinguishing it from the non-lipid-raft VLDLR. Caveolae are a type of lipid raft primarily involved in signaling pathways [80]. Chimeric ApoER2 constructs containing only its cytoplasmic tail do not associate into rafts, suggesting it is the transmembrane or ectodomain involved in the sorting [26]. 
The transmembrane domain of ApoER2 has only 33\% sequence identity compared with VLDLR (Figure 1); this low level of homology may be related to differential sorting of ApoER2 into lipid rafts.

Thus, the different localization of ApoER2 and VLDLR may play a role in their different functions. Reelin is endocytosed via clathrin-coated vesicles and degraded by VLDLR much more efficiently than by ApoER2 [14]. In cell culture experiments, VLDLR facilitated degradation of more than $60 \%$ of bound Reelin after 12 minutes, and all of Reelin by 24 minutes. With ApoER2, after 24 minutes $\sim 75 \%$ of Reelin remained associated with the cells [14]. Disruption of raft structures increased ApoER2-mediated Reelin endocytosis to the rate of VLDLR, indicating that ApoER2's localization in rafts results in reduced endocytosis. Reelin-binding resulted in a lysosomal (rather than proteosomal) degradation of ApoER2 but not of VLDLR, independent of raft-association [14]. However, ApoER2 bound by the non-clustering ligand RAP (receptor-associated protein) did not result in down regulation, suggesting that degradation is mediated by receptor clustering [14]. Thus, ApoER2 may be more important for the mediation of Reelin signaling in lipid rafts, and VLDLR may be more important for the intracellular degradation of Reelin.

\section{Neuronal signaling}

Activation of ApoE receptors directly promotes signal cascades involving the intracellular adaptor protein Dab1, increased activation of SFKs, and decreased activation of JNK [81]. Indirect activation of signaling involving calcium-mediated signal transduction pathways occurs through modification and subsequent increase in NMDAR conductance, which in turn can activate the extracellular signal-related kinases 1/2 (ERK1/2) [29,82]. It is unclear what the specific contributions are for each ApoE receptor or ligand; however, the use of the ligand Reelin has allowed for the identification of at least three specific pathways associated with ApoER2 and VLDLR activation. First, acute Reelin application to hippocampal slices results in NMDA receptor phosphorylation of both NR2A and NR2B subunits that is dependent on Src activation $[28,29,67]$. Second, chronic Reelin treatment of cultured hippocampal neurons shows a significant decrease in the number of silent synapses by increasing AMPA receptor insertion at synaptic terminals that is dependent on PI3K signaling [83]. Third, ApoE receptors affect the activation state on JNK through unstudied mechanisms $[28,29,67]$. JNK-interacting proteins JIP-1 and JIP-2 interact with exon 19 of ApoER2 [28,29,67], potentially affecting JNK signaling in many processes such as cell proliferation, morphogenesis and apoptosis [66]. In general, the interactions with exon 19 and consequent downstream signaling effects may explain some of the differences observed between ApoER2 and VLDLR.
PSD-95 could act as a link between ApoER2 and NMDA receptors since the PDZ1 domain of PSD-95 binds ApoER2 and the PDZ2 domain of PSD-95 binds NMDA receptor subunits [67]. Thus, the formation of multimeric complexes of signaling proteins with ApoER2 may mediate specific signal transduction mechanisms.

Analysis of ApoER2 and VLDLR knockout mice demonstrate that there are differential contributions of VLDLR and ApoER2 to hippocampal synaptic plasticity. Mice deficient for ApoER2 have a greater deficit in hippocampal area CA1 long-term potentiation (LTP) compared to VLDLR deficient mice, in particular when a theta-burst high frequency stimulation protocol is used [82]. The addition of Reelin can enhance LTP, but this requires the presence of both receptors [29,82]. This dual receptor dependency may reflect the necessity for the activation of signal transduction pathways from both receptors (described above) or the need for ApoER2/VLDLR clustering during Reelin binding. Nevertheless, current experimental evidence suggests that ApoER2 plays a signaling role independent of VLDLR. For example, the in vitro increase in LTP in the presence of Reelin requires interaction between ApoER2 and NMDA receptors through exon 19 of ApoER2 [28,29,67]. ApoER2 knockout mice or mice lacking exon 19 of ApoER2 show no Reelin-dependent changes in NMDARs or increase in LTP induction.

\section{Conclusions}

VLDLR and ApoER2 have homologous extracellular and intracellular domains and each is important for Reelinmediated neuronal migration that depends on Dab1. Both undergo a series of proteolytic events that result in soluble forms of the receptors and intracellular domains, and that regulate active receptor levels. However, VLDLR and ApoER2 also interact with different ligands that define separate roles for these receptors in various signaling pathways. VLDLR has a broader tissue distribution and interacts specifically with the Pafah1b complex. ApoER2 is found in lipid rafts and interacts with PSD-95 and JIPs through a unique alternatively spliced sequence. These interactions affect signaling pathways regulated by intracellular calcium levels and JNK. As we continue to examine these receptors, we will better define their unique roles in neuronal migration and synaptic signaling.

\section{Acknowledgements}

Drs. Weeber and Rebeck are supported by NIH grants P01 AG030128 and R01 AG035379.

\section{Author details}

'Department of Biology; Georgetown University, $37^{\text {th }}$ and O Streets, NW, Washington, DC, 20057, USA. ²Department of Neuroscience; Georgetown University Medical Center, 3970 Reservoir Rd, NW, Washington, DC, 20007 USA. ${ }^{3}$ Department of Molecular Pharmacology \& Physiology; University of South Florida, 4001 E. Fletcher Ave., Tampa, FL, 33612-4742, USA. 


\section{Authors' contributions}

SSR did the literature review on ApoER2 and VLDLR comparisons, and TEC compiled and analyzed data. EJW and GWR suggested topics and edited the manuscript. All authors read and approved the final manuscript.

\section{Competing interests}

The authors declare that they have no competing interests.

Received: 19 January 2011 Accepted: 9 May 2011 Published: 9 May 2011

\section{References}

1. Beffert U, Stolt PC, Herz J: Functions of lipoprotein receptors in neurons. J Lipid Res 2004, 45:403-409.

2. Kim DH, lijima H, Goto K, Sakai J, Ishii H, Kim HJ, Suzuki H, Kondo H, Saeki S, Yamamoto T: Human apolipoprotein E receptor 2. A novel lipoprotein receptor of the low density lipoprotein receptor family predominantly expressed in brain. J Biol Chem 1996, 271:8373-8380.

3. Tissir F, Goffinet AM: Reelin and brain development. Nat Rev Neurosci 2003, 4:496-505

4. D'Arcangelo G, Miao GG, Chen SC, Soares HD, Morgan Jl, Curran T: A protein related to extracellular matrix proteins deleted in the mouse mutant reeler. Nature 1995, 374:719-723.

5. Trommsdorff M, Gotthardt M, Hiesberger T, Shelton J, Stockinger W, Nimpf J, Hammer RE, Richardson JA, Herz J: Reeler/Disabled-like disruption of neuronal migration in knockout mice lacking the VLDL receptor and ApoE receptor 2. Cell 1999, 97:689-701.

6. D'Arcangelo G, Homayouni R, Keshvara L, Rice DS, Sheldon M, Curran T: Reelin is a ligand for lipoprotein receptors. Neuron 1999, 24:471-479.

7. Howell BW, Hawkes R, Soriano P, Cooper JA: Neuronal position in the developing brain is regulated by mouse disabled-1. Nature 1997. 389:733-737.

8. Morimura T, Ogawa M: Relative importance of the tyrosine phosphorylation sites of Disabled-1 to the transmission of Reelin signaling. Brain Res 2009, 1304:26-37.

9. Strasser V, Fasching D, Hauser C, Mayer H, Bock HH, Hiesberger T, Herz J, Weeber EJ, Sweatt JD, Pramatarova A, et al: Receptor clustering is involved in Reelin signaling. Mol Cell Biol 2004, 24:1378-1386.

10. Benhayon D, Magdaleno S, Curran T: Binding of purified Reelin to ApoER2 and VLDLR mediates tyrosine phosphorylation of Disabled-1. Brain Res Mol Brain Res 2003, 112:33-45.

11. Rakic P, Caviness VS Jr: Cortical development: view from neurological mutants two decades later. Neuron 1995, 14:1101-1104.

12. Sheldon M, Rice DS, D'Arcangelo G, Yoneshima H, Nakajima K, Mikoshiba K, Howell BW, Cooper JA, Goldowitz D, Curran T: Scrambler and yotari disrupt the disabled gene and produce a reeler-like phenotype in mice. Nature 1997, 389:730-733.

13. Kubo K, Mikoshiba K, Nakajima K: Secreted Reelin molecules form homodimers. Neurosci Res 2002, 43:381-388.

14. Duit S, Mayer H, Blake SM, Schneider WJ, Nimpf J: Differential functions of ApoER2 and very low density lipoprotein receptor in Reelin signaling depend on differential sorting of the receptors. J Biol Chem 2010, 285:4896-4908.

15. Bock HH, Jossin Y, May P, Bergner O, Herz J: Apolipoprotein E receptors are required for reelin-induced proteasomal degradation of the neuronal adaptor protein Disabled-1. J Biol Chem 2004, 279:33471-33479.

16. Strittmatter WJ, Roses AD: Apolipoprotein E and Alzheimer's disease. Annu Rev Neurosci 1996, 19:53-77.

17. Oka K, Tzung KW, Sullivan M, Lindsay E, Baldini A, Chan L: Human verylow-density lipoprotein receptor complementary DNA and deduced amino acid sequence and localization of its gene (VLDLR) to chromosome band 9 p24 by fluorescence in situ hybridization. Genomics 1994, 20:298-300.

18. Oka K, Ishimura-Oka K, Chu MJ, Sullivan M, Krushkal J, Li WH, Chan L: Mouse very-low-density-lipoprotein receptor (VLDLR) cDNA cloning, tissue-specific expression and evolutionary relationship with the lowdensity-lipoprotein receptor. Eur J Biochem 1994, 224:975-982.

19. Christie RH, Chung H, Rebeck GW, Strickland D, Hyman BT: Expression of the very low-density lipoprotein receptor (VLDL-r), an apolipoprotein-E receptor, in the central nervous system and in Alzheimer's disease. J Neuropathol Exp Neurol 1996, 55:491-498.
20. Sakai K, Tiebel O, Ljungberg MC, Sullivan M, Lee HJ, Terashima T, Li R, Kobayashi K, Lu HC, Chan L, Oka K: A neuronal VLDLR variant lacking the third complement-type repeat exhibits high capacity binding of apoE containing lipoproteins. Brain Res 2009, 1276:11-21.

21. Clatworthy AE, Stockinger W, Christie RH, Schneider WJ, Nimpf J, Hyman BT, Rebeck GW: Expression and alternate splicing of apolipoprotein $E$ receptor 2 in brain. Neuroscience 1999, 90:903-911.

22. Perez-Garcia CG, Tissir F, Goffinet AM, Meyer G: Reelin receptors in developing laminated brain structures of mouse and human. Eur J Neurosci 2004, 20:2827-2832.

23. Hack I, Hellwig S, Junghans D, Brunne B, Bock HH, Zhao S, Frotscher M: Divergent roles of ApoER2 and VIdlr in the migration of cortical neurons. Development 2007, 134:3883-3891.

24. Nakamura Y, Yamamoto M, Kumamaru E: Significance of the variant and full-length forms of the very low density lipoprotein receptor in brain. Brain Res 2001, 922:209-215.

25. Brandes C, Kahr L, Stockinger W, Hiesberger T, Schneider WJ, Nimpf J: Alternative splicing in the ligand binding domain of mouse ApoE receptor-2 produces receptor variants binding reelin but not alpha 2macroglobulin. J Biol Chem 2001, 276:22160-22169.

26. Mayer H, Duit S, Hauser C, Schneider WJ, Nimpf J: Reconstitution of the Reelin signaling pathway in fibroblasts demonstrates that Dab1 phosphorylation is independent of receptor localization in lipid rafts. Mol Cell Biol 2006, 26:19-27.

27. Hibi T, Mizutani M, Baba A, Hattori M: Splicing variations in the ligandbinding domain of ApoER2 results in functional differences in the binding properties to Reelin. Neurosci Res 2009, 63:251-258.

28. Stockinger W, Brandes C, Fasching D, Hermann M, Gotthardt M, Herz J, Schneider WJ, Nimpf J: The reelin receptor ApoER2 recruits JNKinteracting proteins-1 and -2. J Biol Chem 2000, 275:25625-25632.

29. Beffert U, Weeber EJ, Durudas A, Qiu S, Masiulis I, Sweatt JD, Li WP, Adelmann G, Frotscher M, Hammer RE, Herz J: Modulation of synaptic plasticity and memory by Reelin involves differential splicing of the lipoprotein receptor Apoer2. Neuron 2005, 47:567-579.

30. Hoe HS, Rebeck GW: Functional interactions of APP with the apoE receptor family. J Neurochem 2008, 106:2263-2271.

31. Gotthardt M, Trommsdorff M, Nevitt MF, Shelton J, Richardson JA, Stockinger W, Nimpf J, Herz J: Interactions of the low density lipoprotein receptor gene family with cytosolic adaptor and scaffold proteins suggest diverse biological functions in cellular communication and signal transduction. J Biol Chem 2000, 275:25616-25624.

32. May P, Bock HH, Nimpf J, Herz J: Differential glycosylation regulates processing of lipoprotein receptors by gamma-secretase. J Biol Chem 2003, 278:37386-37392

33. Hoe HS, Rebeck GW: Regulation of ApoE receptor proteolysis by ligand binding. Brain Res Mol Brain Res 2005, 137:31-39.

34. Hiesberger T, Trommsdorff M, Howell BW, Goffinet A, Mumby MC, Cooper JA, Herz J: Direct binding of Reelin to VLDL receptor and ApoE receptor 2 induces tyrosine phosphorylation of disabled-1 and modulates tau phosphorylation. Neuron 1999, 24:481-489.

35. Nakano Y, Kohno T, Hibi T, Kohno S, Baba A, Mikoshiba K, Nakajima K, Hattori M: The extremely conserved C-terminal region of Reelin is not necessary for secretion but is required for efficient activation of downstream signaling. J Biol Chem 2007, 282:20544-20552.

36. Yasui N, Nogi T, Takagi J: Structural basis for specific recognition of reelin by its receptors. Structure 2010, 18:320-331.

37. Lambert de Rouvroit C, Bernier B, Royaux I, de Bergeyck V, Goffinet AM: Evolutionarily conserved, alternative splicing of reelin during brain development. Exp Neurol 1999, 156:229-238.

38. Jossin $\mathrm{Y}$, Ignatova $\mathrm{N}$, Hiesberger $\mathrm{T}$, Herz J, Lambert de Rouvroit $\mathrm{C}$, Goffinet AM: The central fragment of Reelin, generated by proteolytic processing in vivo, is critical to its function during cortical plate development. J Neurosci 2004, 24:514-521.

39. Ruiz J, Kouiavskaia D, Migliorini M, Robinson S, Saenko EL, Gorlatova N, Li D, Lawrence D, Hyman BT, Weisgraber KH, Strickland DK: The apoE isoform binding properties of the VLDL receptor reveal marked differences from LRP and the LDL receptor. J Lipid Res 2005, 46:1721-1731.

40. Chen Y, Durakoglugil MS, Xian X, Herz J: ApoE4 reduces glutamate receptor function and synaptic plasticity by selectively impairing ApoE receptor recycling. Proc Natl Acad Sci USA 2010, 107:12011-12016. 
41. Adams JC: Thrombospondins: multifunctional regulators of cell interactions. Annu Rev Cell Dev Biol 2001, 17:25-51.

42. Christopherson KS, Ullian EM, Stokes CC, Mullowney CE, Hell JW, Agah A, Lawler J, Mosher DF, Bornstein P, Barres BA: Thrombospondins are astrocyte-secreted proteins that promote CNS synaptogenesis. Cell 2005, 120:421-433

43. Blake SM, Strasser V, Andrade N, Duit S, Hofbauer R, Schneider WJ, Nimpf J: Thrombospondin-1 binds to ApoER2 and VLDL receptor and functions in postnatal neuronal migration. Embo J 2008, 27:3069-3080.

44. Klar A, Baldassare M, Jessell TM: F-spondin: a gene expressed at high levels in the floor plate encodes a secreted protein that promotes neural cell adhesion and neurite extension. Cell 1992, 69:95-110.

45. Hoe HS, Wessner D, Beffert U, Becker AG, Matsuoka Y, Rebeck GW: Fspondin interaction with the apolipoprotein E receptor ApoEr2 affects processing of amyloid precursor protein. Mol Cell Biol 2005, 25:9259-9268.

46. Andrade N, Komnenovic V, Blake SM, Jossin Y, Howell B, Goffinet A, Schneider WJ, Nimpf J: ApoER2/VLDL receptor and Dab1 in the rostral migratory stream function in postnatal neuronal migration independently of Reelin. Proc Natl Acad Sci USA 2007, 104:8508-8513.

47. Peterziel H, Sackmann T, Strelau J, Kuhn PH, Lichtenthaler SF, Marom K, Klar A, Unsicker K: F-spondin regulates neuronal survival through activation of disabled-1 in the chicken ciliary ganglion. Mol Cell Neurosci 2011, 46:483-497.

48. Olson GE, Winfrey VP, Nagdas SK, Hill KE, Burk RF: Apolipoprotein E receptor-2 (ApoER2) mediates selenium uptake from selenoprotein $\mathrm{P}$ by the mouse testis. J Biol Chem 2007, 282:12290-12297.

49. Burk RF, Hill KE, Olson GE, Weeber EJ, Motley AK, Winfrey VP, Austin LM: Deletion of apolipoprotein E receptor- 2 in mice lowers brain selenium and causes severe neurological dysfunction and death when a lowselenium diet is fed. J Neurosci 2007, 27:6207-6211.

50. Valentine WM, Abel TW, Hill KE, Austin LM, Burk RF: Neurodegeneration in mice resulting from loss of functional selenoprotein $\mathrm{P}$ or its receptor apolipoprotein E receptor 2. J Neuropathol Exp Neurol 2008, 67:68-77.

51. Poirier S, Mayer G, Benjannet S, Bergeron E, Marcinkiewicz J, Nassoury N, Mayer H, Nimpf J, Prat A, Seidah NG: The proprotein convertase PCSK9 induces the degradation of low density lipoprotein receptor (LDLR) and its closest family members VLDLR and ApoER2. J Biol Chem 2008, 283:2363-2372.

52. Maxwell KN, Breslow JL: Adenoviral-mediated expression of Pcsk9 in mice results in a low-density lipoprotein receptor knockout phenotype. Proc Natl Acad Sci USA 2004, 101:7100-7105.

53. Park SW, Moon YA, Horton JD: Post-transcriptional regulation of low density lipoprotein receptor protein by proprotein convertase subtilisin/ kexin type 9a in mouse liver. J Biol Chem 2004, 279:50630-50638.

54. Hong C, Duit S, Jalonen P, Out R, Scheer L, Sorrentino V, Boyadjian R, Rodenburg KW, Foley E, Korhonen L, et al: The E3 ubiquitin ligase IDOL induces the degradation of the low density lipoprotein receptor family members VLDLR and ApoER2. J Biol Chem 2010, 285:19720-19726.

55. Stolt PC, Jeon H, Song HK, Herz J, Eck MJ, Blacklow SC: Origins of peptide selectivity and phosphoinositide binding revealed by structures of disabled-1 PTB domain complexes. Structure 2003, 11:569-579.

56. Howell BW, Gertler FB, Cooper JA: Mouse disabled (mDab1): a Src binding protein implicated in neuronal development. Embo J 1997, 16:121-132.

57. Morimura T, Hattori M, Ogawa M, Mikoshiba K: Disabled1 regulates the intracellular trafficking of reelin receptors. J Biol Chem 2005, 280:16901-16908.

58. Hoe HS, Tran TS, Matsuoka Y, Howell BW, Rebeck GW: DAB1 and Reelin effects on amyloid precursor protein and ApoE receptor 2 trafficking and processing. J Biol Chem 2006, 281:35176-35185.

59. Cheung KK, Mok SC, Rezaie P, Chan WY: Dynamic expression of Dab2 in the mouse embryonic central nervous system. BMC Dev Biol 2008, 8:76.

60. Yang DH, Smith ER, Roland IH, Sheng Z, He J, Martin WD, Hamilton TC, Lambeth JD, Xu XX: Disabled-2 is essential for endodermal cell positioning and structure formation during mouse embryogenesis. Dev Biol 2002, 251:27-44.

61. Zhou J, Scholes J, Hsieh JT: Characterization of a novel negative regulator (DOC-2/DAB2) of c-Src in normal prostatic epithelium and cancer. J Biol Chem 2003, 278:6936-6941.

62. Cuitino L, Matute R, Retamal C, Bu G, Inestrosa NC, Marzolo MP: ApoER2 is endocytosed by a clathrin-mediated process involving the adaptor protein Dab2 independent of its Rafts' association. Traffic 2005, 6:820-838.
63. Reiner O, Carrozzo R, Shen Y, Wehnert M, Faustinella F, Dobyns WB, Caskey $C T$, Ledbetter DH: Isolation of a Miller-Dieker lissencephaly gene containing $\mathrm{G}$ protein beta-subunit-like repeats. Nature 1993, 364:717-721.

64. Assadi AH, Zhang G, Beffert U, McNeil RS, Renfro AL, Niu S, Quattrocchi CC, Antalffy BA, Sheldon M, Armstrong DD, et al: Interaction of reelin signaling and Lis1 in brain development. Nat Genet 2003, 35:270-276.

65. Zhang G, Assadi AH, McNeil RS, Beffert U, Wynshaw-Boris A, Herz J, Clark GD, D'Arcangelo G: The Pafah1b complex interacts with the reelin receptor VLDLR. PLoS One 2007, 2:e252.

66. Whitmarsh AJ: The JIP family of MAPK scaffold proteins. Biochem Soc Trans 2006, 34:828-832.

67. Hoe HS, Pocivavsek A, Chakraborty G, Fu Z, Vicini S, Ehlers MD, Rebeck GW: Apolipoprotein E receptor 2 interactions with the N-methyl-D-aspartate receptor. J Biol Chem 2006, 281:3425-3431.

68. Russo T, Faraonio R, Minopoli G, De Candia P, De Renzis S, Zambrano N: Fe65 and the protein network centered around the cytosolic domain of the Alzheimer's beta-amyloid precursor protein. FEBS Lett 1998, 434:1-7.

69. Hoe HS, Magill LA, Guenette S, Fu Z, Vicini S, Rebeck GW: FE65 interaction with the ApoE receptor ApoEr2. J Biol Chem 2006, 281:24521-24530.

70. Guenette SY, Chen J, Jondro PD, Tanzi RE: Association of a novel human FE65-like protein with the cytoplasmic domain of the beta-amyloid precursor protein. Proc Natl Acad Sci USA 1996, 93:10832-10837.

71. Sabo SL, Ikin AF, Buxbaum JD, Greengard P: The Alzheimer amyloid precursor protein (APP) and FE65, an APP-binding protein, regulate cell movement. J Cell Biol 2001, 153:1403-1414.

72. Guenette S, Chang Y, Hiesberger T, Richardson JA, Eckman CB, Eckman EA, Hammer RE, Herz J: Essential roles for the FE65 amyloid precursor protein-interacting proteins in brain development. Embo J 2006, 25:420-431.

73. Howell BW, Herrick TM, Hildebrand JD, Zhang Y, Cooper JA: Dab1 tyrosine phosphorylation sites relay positional signals during mouse brain development. Curr Biol 2000, 10:877-885.

74. Herz J, Bock HH: Lipoprotein receptors in the nervous system. Annu Rev Biochem 2002, 71:405-434.

75. Hong SE, Shugart YY, Huang DT, Shahwan SA, Grant PE, Hourihane JO, Martin ND, Walsh CA: Autosomal recessive lissencephaly with cerebellar hypoplasia is associated with human RELN mutations. Nat Genet 2000, 26:93-96.

76. Boycott KM, Flavelle S, Bureau A, Glass HC, Fujiwara TM, Wirrell E, Davey K, Chudley AE, Scott JN, McLeod DR, Parboosingh JS: Homozygous deletion of the very low density lipoprotein receptor gene causes autosomal recessive cerebellar hypoplasia with cerebral gyral simplification. Am J Hum Genet 2005, 77:477-483.

77. Zhang G, Assadi AH, Roceri M, Clark GD, D'Arcangelo G: Differential interaction of the Pafah $1 \mathrm{~b}$ alpha subunits with the Reelin transducer Dab1. Brain Res 2009, 1267:1-8.

78. Hattori M, Adachi $H$, Tsujimoto M, Arai $H$, Inoue K: Miller-Dieker lissencephaly gene encodes a subunit of brain platelet-activating factor acetylhydrolase [corrected]. Nature 1994, 370:216-218.

79. Bi W, Sapir T, Shchelochkov OA, Zhang F, Withers MA, Hunter JV, Levy T, Shinder V, Peiffer DA, Gunderson KL, et al: Increased LIS1 expression affects human and mouse brain development. Nat Genet 2009, 41:168-177.

80. Riddell DR, Sun XM, Stannard AK, Soutar AK, Owen JS: Localization of apolipoprotein $\mathrm{E}$ receptor 2 to caveolae in the plasma membrane. J Lipid Res 2001, 42:998-1002.

81. Hoe HS, Harris DC, Rebeck GW: Multiple pathways of apolipoprotein E signaling in primary neurons. J Neurochem 2005, 93:145-155.

82. Weeber EJ, Beffert U, Jones C, Christian JM, Forster E, Sweatt JD, Herz J: Reelin and ApoE receptors cooperate to enhance hippocampal synaptic plasticity and learning. J Biol Chem 2002, 277:39944-39952.

83. Qiu S, Weeber EJ: Reelin signaling facilitates maturation of CA1 glutamatergic synapses. J Neurophysiol 2007, 97:2312-2321.

doi:10.1186/1750-1326-6-30

Cite this article as: Reddy et al:: Similarities and differences in structure, expression, and functions of VLDLR and ApoER2. Molecular Neurodegeneration 2011 6:30. 